\title{
Short Communication: Change in Plasma Ghrelin in Dairy Cows Following an Intravenous Glucose Challenge
}

\author{
J. R. Roche, ${ }^{* 1}$ A. J. Sheahan, ${ }^{*}$ L. M. Chagas, ${ }^{*}$ and R. C. Boston† \\ *DairyNZ, Private Bag 3221, Hamilton, New Zealand \\ †Department of Clinical Studies, New Bolton Center, University of Pennsylvania, Philadelphia 19104
}

\begin{abstract}
Ghrelin is an endogenous ligand of the growth hormone secretagogue receptor and a potent orexigenic (appetite-stimulating) agent in humans and rodents, but little is known about its effect in dairy cows. Ten multiparous dairy cows $35 \mathrm{~d}$ in milk were subjected to an i.v. glucose challenge ( $300 \mathrm{mg}$ of D-glucose/ $\mathrm{kg}$ of body weight). Before infusion and at regular intervals after infusion, plasma glucose, insulin, nonesterified fatty acids (NEFA), growth hormone, epinephrine, and ghrelin concentrations were monitored. Plasma insulin rose (27.2 $\mathrm{mU} / \mathrm{L}$ at $10 \mathrm{~min})$ and NEFA, epinephrine, and ghrelin declined (nadir $=0.22 \mathrm{mmol} / \mathrm{L}, 22.2 \mu \mathrm{g} / \mathrm{L}$, and $272 \mu \mathrm{g} / \mathrm{L}$ at 31,13 , and $22 \mathrm{~min}$, respectively) after the glucose infusion. Ghrelin declined for $22 \mathrm{~min}$ before returning to suprabasal levels at approximately 75 min postinfusion. Sequential changes of the hormones and metabolites suggested a glucose transporter, type 2- and glucose transporter, type 4-mediated disposal of glucose, and an insulin-mediated reduction in NEFA. Ghrelin and epinephrine declined after glucose infusion and before the insulin peak, but the effect of insulin as a controlling factor in the hyperglycemic reduction in these hormones cannot be discounted. The postnadir surge in ghrelin may be regulated by the decline in circulating concentrations of glucose and NEFA (an energy-deficit signal). The profile of change in plasma ghrelin in lactating dairy cows after a glucose challenge was similar to that in monogastric animals.
\end{abstract}

Key words: intake regulation, neuroendocrine factor, glucose challenge, lipolysis

Ghrelin, an endogenous ligand for the growth hormone secretagogue receptor, is produced predominantly in the oxyntic cells of the stomach and aboma-

Received August 2, 2007.

Accepted November 28, 2007.

${ }^{1}$ Corresponding author: john.roche@dairynz.co.nz sum and is a potent orexigenic agent in rodents (Tschop et al., 2000) and humans (Wren et al., 2001), yet little information is available on the effect of ghrelin on feed intake in dairy cows. Despite this, many of the effects of ghrelin evident in human and rodent models have been reported in ruminants. For example, Sugino et al. (2002) reported a preprandial transient surge and a postprandial decline in plasma ghrelin in sheep that was modified by the feeding regimen. Similarly, Roche et al. (2007) reported a postprandial decline in plasma ghrelin concentrations in dairy cows. Wertz-Lutz et al. (2006) reported an increase in time spent feeding and DMI in beef cattle injected i.v. with sufficient ghrelin to raise postprandial ghrelin concentrations to preprandial levels. Roche et al. (2007) identified a negative relationship between plasma ghrelin and BCS in dairy cows, a trend consistent with elevated plasma ghrelin in human subjects suffering from anorexia nervosa and the reduced plasma ghrelin concentration in obese human subjects (Shiiya et al., 2002; Nakai et al., 2003).

Data presented from monogastric studies indicate a decline in plasma ghrelin following oral and i.v. glucose infusions (Shiiya et al., 2002; Nakai et al., 2003), which is consistent with the reported postprandial decline. However, glucose metabolism in dairy cows differs greatly from that in nonlactating monogastric animals, particularly in early lactation when significant quantities of glucose are required for milk production. Little glucose escapes the rumen for intestinal absorption, with hepatic and renal gluconeogenesis providing for glucose requirements (Reynolds, 2006). In addition, early-lactation dairy cows exhibit elevated growth hormone and NEFA, low IGF-I and insulin (Hart et al., 1978), and a reduced sensitivity to circulating insulin. All of these characteristics may lead to a different plasma ghrelin response profile in dairy cows following a glucose infusion than previously reported in monogastric animals. The objectives were to capture the patterns of variation in plasma ghrelin in lactating cows in response to an i.v. glucose challenge (IVGC), and to depict the sequential nature of the patterns of variation in key substrates and hormones in an attempt to 
estimate cause-and-effect associations or temporal synchrony.

Ten Holstein-Friesian dairy cows $(2.5 \pm 1.27$ lactations; $26.4 \pm 5.35 \mathrm{~kg}$ of milk/d; $4.9 \pm 0.85 \%$ fat; $3.9 \pm$ $0.34 \%$ protein; $4.7 \pm 0.16 \%$ lactose; $567 \pm 95.3 \mathrm{~kg}$ of BW; $5.0 \pm 0.50$ BCS units on a 1 to 10 scale) were randomly selected from an existing research trial (Roche et al., 2007) and subjected to an IVGC at $35 \pm$ 2.3 DIM. On the day before the IVGC, a catheter (14 gauge $\times 19.6 \mathrm{~cm}$; Delmed, New Brunswick, NJ) was inserted into the jugular vein of each cow. Patency was maintained with $3.5 \%$ sodium citrate in sterile saline. Food was withheld for $12 \mathrm{~h}$ before the IVGC. A sterile solution of glucose $(50 \% \mathrm{wt} / \mathrm{vol})$ was warmed to body temperature and administered i.v. through the catheter (300 mg of D-glucose/kg of BW) at a constant rate by manually compressing the glucose pack. The infusion was completed within 2 min. Two evacuated $10-\mathrm{mL}$ blood collection tubes (140 IU of sodium heparin and $0.117 \mathrm{~mL}$ of $15 \% \mathrm{~K}_{3} \mathrm{EDTA}$ ) were collected from each cow $2 \mathrm{~min}$ before the infusion ( $-2 \mathrm{~min}$ ), immediately before infusion ( $0 \mathrm{~min}$ ), and $2,4,6,8,10,12,15,18$, $20,23,26,30,35,40,50,60,90,120,150,180,210$, and $240 \mathrm{~min}$ after completing the infusion. After centrifugation $\left(1,120 \times g, 10 \mathrm{~min}, 4^{\circ} \mathrm{C}\right)$ and extraction, plasma from the EDTA-blood tubes was acidified with $0.1 \mathrm{~N} \mathrm{HCl}$ and treated with phenylmethylsulfonyl fluoride $\left(\mathrm{C}_{7} \mathrm{H}_{7} \mathrm{FO}_{2} \mathrm{~S}\right)$ according to kit instructions (Ghrelin Active Kit, Linco, St. Charles, MO) before storage and analysis for plasma ghrelin concentration.

Plasma samples were analyzed by Alpha Scientific Ltd. (Hamilton, NZ) for NEFA (colorimetric method) and glucose (hexokinase method) with a Hitachi 717 analyzer (Roche, Basel, Switzerland) at $30^{\circ} \mathrm{C}$. The inter- and intraassay coefficients of variation were $<2 \%$ for both assays. Plasma growth hormone (Downing et al., 1995) and insulin (Hales and Randle, 1963) concentrations were determined by using a double-antibody RIA with inter- and intraassay coefficients of variation of $<10 \%$. Plasma samples for epinephrine analysis were extracted by using aluminum oxide and measured by HPLC with electrochemical detection as described by Goldstein et al. (1981). The limit of detection was $4 \mathrm{pg} / \mathrm{mL}$ of plasma based on extraction from 1 $\mathrm{mL}$ of sample. Samples were analyzed once, but the coefficient of variation for repeated samples was $2.9 \%$. Plasma ghrelin concentrations were determined by using the Linco Active RIA Kit (GHRA-88HK, Millipore Corporation, Billerica, MA), which uses a double-antibody/polyethyleneglycol technique. The kit was specific for the biologically active form of ghrelin, and used ${ }^{125}$ I-labeled ghrelin and a ghrelin antiserum (Wertz-Lutz et al., 2006). The inter- and intraassay coefficients of variation were 6.4 and $7.3 \%$, respectively.

All values of each metabolite or hormone before and including time point 0 were averaged to display the baseline status of each metabolite. Because the goals of this investigation were to capture the patterns of variation of key substrates and hormones, and then to expose the sequential structure of the patterns of variation in conjunction with an IVGC, 2 distinct and metabolite-dependent approaches to summarizing the profiles were refined. For the well-regulated and fairly well-structured substrate (NEFA and glucose) responses, and for the more volatile and pulsatile hormones (epinephrine and ghrelin), local polynomial means smoothing was used (Gutierrez et al., 2003). To accommodate differences in the metabolic subgroups, polynomials for the hormones were limited to degree 4, but the substrate (hormone or metabolite) smoothers were allowed to venture to degree 6 . We were guided by the consistency of the smoothed fit to the observed means, by the identification of each polynomial contribution to the overall fit, and by the marginal improvement (sequential F-statistic) of the additional terms in the overall fit to isolate the appropriate polynomial form.

The insulin and growth hormone profiles displayed common and uniquely distinct traits that were not easily captured by using local polynomial smoothing, so the mean temporal profiles were displayed by using gamma functions. The polynomial smoothing was accomplished by using Stata's "locpoly" and "fracpoly" utilities. The nonlinear gamma function was fitted by using Stata's "nl" utility. All analyses reported were performed with the aid of Stata 9.2 (StataCorp, 2005).

The mean concentrations of glucose, insulin, ghrelin, NEFA, epinephrine, and growth hormone relative to the time of glucose infusion, and the associated fitted models are presented in Figure 1. All functions fitted well, with adjusted $R^{2}$ of $0.99,0.99,0.99,0.95$, 0.79 , and 0.99 , and a root mean square error of 0.089 , $0.90,0.018,38.88,4.63$, and 0.43 for glucose, insulin, NEFA, ghrelin, epinephrine, and growth hormone, respectively.

The presented profiles of change in plasma glucose, insulin, and NEFA with glucose infusion are consistent with previous IVGC studies reported in dairy cattle (Gaynor et al., 1996; Sumner et al., 2007), but the profile of plasma ghrelin change in dairy cows has not been published previously.

Plasma glucose concentration reached supraphysiological concentrations $(14.6 \pm 1.23 \mathrm{mmol} / \mathrm{L}$; mean \pm $\mathrm{SD})$ within $2 \mathrm{~min}$ of infusion before returning to baseline $(3.0 \pm 0.45 \mathrm{mmol} / \mathrm{L})$ by $90 \mathrm{~min}$. Consistent with its role in glucose disposal, insulin concentration in- 

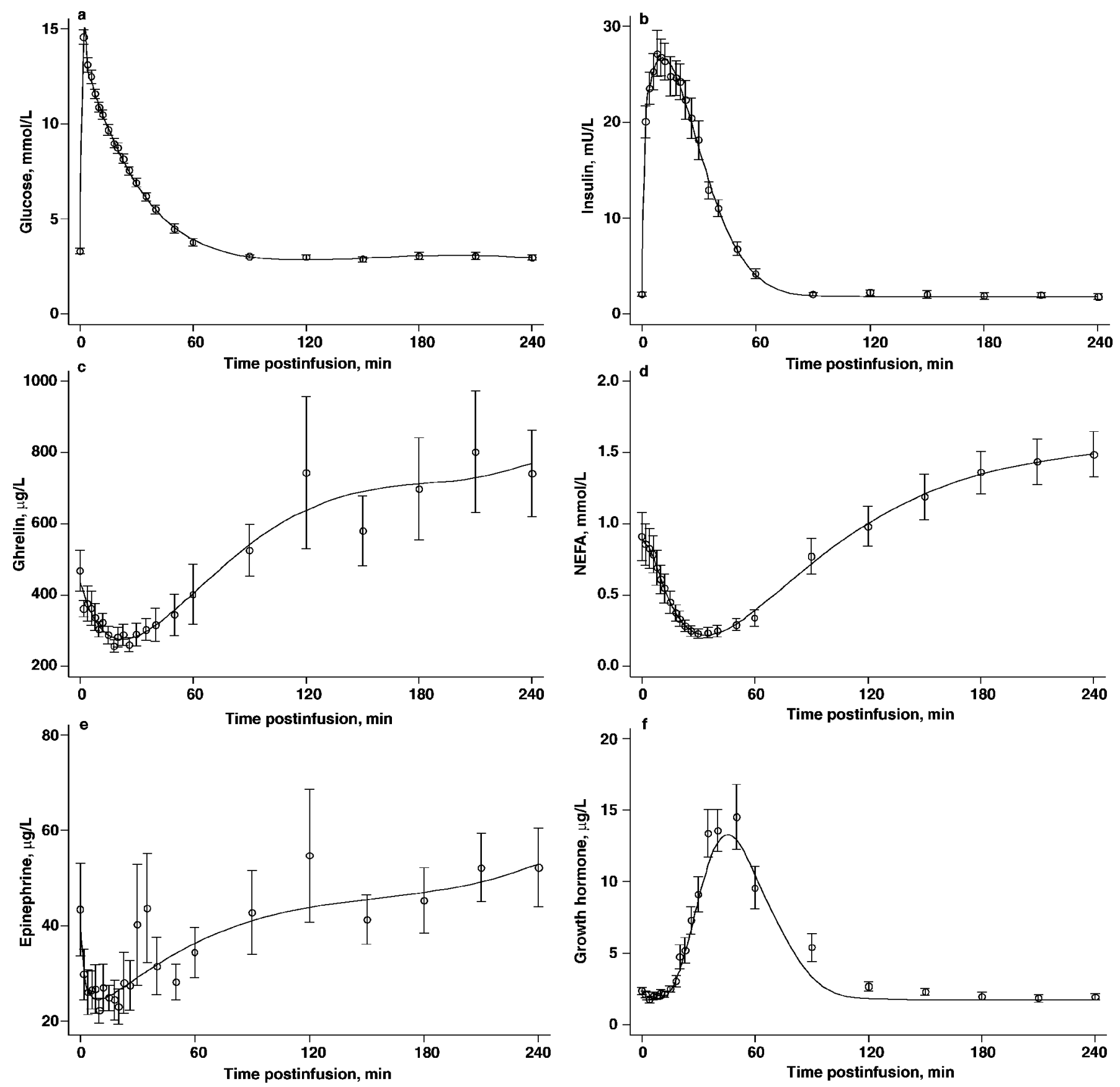

Figure 1. The mean response profile of glucose (a), insulin (b), ghrelin (c), NEFA (d), epinephrine (e), and growth hormone (f) in earlylactating dairy cows $(n=10)$ to a jugular infusion of $300 \mathrm{mg}$ of $\mathrm{D}$-glucose/kg of $\mathrm{BW}$. The presented lines are smoothed polynomials.

creased after the glucose infusion, peaking at $27.2 \pm$ $7.54 \mathrm{mU} / \mathrm{L}$ at $10 \pm 4.1 \mathrm{~min}$ postinfusion and declining more rapidly than glucose to reach baseline $(2.1 \pm 0.52$ $\mathrm{mU} / \mathrm{L})$ at approximately the same time $(90 \mathrm{~min})$. Plasma ghrelin concentration was expected to be elevated at 0 min as a result of the 12-h fast (Wertz-Lutz et al., 2006), and declined rapidly after infusion of the glucose bolus, consistent with the postprandial decline in plasma ghrelin reported previously (Sugino et al., 2002; Roche et al., 2007). The nadir for ghrelin (272 \pm $74.4 \mu \mathrm{g} / \mathrm{L}$ ) was reached at $22 \pm 9.7 \mathrm{~min}$ before increasing beyond preinfusion concentrations at approximately 75 min postinfusion. Concentrations had not returned to baseline after $4 \mathrm{~h}$, when sampling ceased. 
In comparison with the immediate and rapid decline in plasma ghrelin, NEFA concentrations declined slowly for 6 min postinfusion, most likely as a result of fatty acid oxidation, considering the preinfusion period of fasting, before declining rapidly under the direct effect of increased circulating insulin (Ferranini et al., 1997), to a nadir of $0.22 \pm 0.11 \mathrm{mmol} / \mathrm{L}$ at $31 \pm$ 3.4 min postinfusion.

The initial rapid decline in plasma glucose occurred several minutes before the peak insulin response, implicating glucose transporter, type 2 (GLUT2) as the immediate disposal mediators, with insulin facilitating the continued reduction through GLUT4-mediated uptake of glucose by muscle and adipose tissue (Nelson and Cox, 2005). The GLUT2 is expressed primarily in the liver, pancreas, and small intestine, and its primary role is the hepatic removal of excess glucose from the blood and the regulation of insulin release. In contrast to the other non-insulin-dependent glucose transporters, which are functioning at a near maximal rate under physiologically normal glucose concentrations, GLUT2 has a low affinity for glucose, enabling an increase in transport rate with increasing blood glucose concentration. Activity of GLUT4 increases when blood insulin signals a high blood glucose concentration and facilitates further uptake of glucose by muscle and adipose tissue.

Insulin facilitates the disposal of glucose by inhibiting lipolysis, reducing the circulating pool of NEFA (Figure 1d) for oxidation, and thereby increasing the tissue demand for circulating glucose. Insulin is a potent regulator of circulating NEFA through provision of $\alpha$-glycerolphosphate, which enables reesterification of fatty acids to triacylglycerols, and through the inhibition of hormone-sensitive lipase (Ferranini et al., 1997) and the up-regulation of genes associated with lipogenic enzymes in adipose tissue (Nelson and Cox, 2005). Therefore, the presented profiles of glucose, insulin, and NEFA were as expected.

The decline in epinephrine was rapid, reaching a nadir $(22.2 \pm 8.33 \mu \mathrm{g} / \mathrm{L})$ in line with peak insulin and increasing to basal concentrations by $90 \mathrm{~min}$. The rise in plasma growth hormone (basal $=2.1 \pm 0.75 \mu \mathrm{g} / \mathrm{L}$; peak $12.0 \pm 4.85 \mu \mathrm{g} / \mathrm{L}$ ) coincided with the epinephrine surge and the decline in plasma insulin. The association between epinephrine and growth hormone secretion was identified previously. Cass Terry et al. (1982) caused complete suppression of episodic growth hormone secretion by preventing epinephrine secretion. These results suggest that the increase in plasma growth hormone concentration (Figure 1f) was likely a result, at least in part, of the simultaneous epinephrine surge.
The sequential pattern of changes in these plasma hormones and metabolites, scaled on a concentration basis, are presented in Figure 2. The plasma ghrelin profile is consistent with the reported postprandial decline in concentrations of the hormone in plasma (Sugino et al., 2002; Roche et al., 2007) and with its decline in humans following both an IVGC and oral glucose supplement (Shiiya et al., 2002). The ghrelin profile was similar to the epinephrine and NEFA profile, and was the inverse of the glucose and insulin profile. But for something to cause an event it must occur before the event. Therefore, the factor controlling ghrelin disposal and secretion must change before the exhibited change in ghrelin. This excludes changes in NEFA as a controlling influence in the postinfusion decline in plasma ghrelin.

Although plasma ghrelin had begun its descent before plasma insulin concentrations peaked, the results presented cannot preclude insulin as a contributing factor toward the presented changes in the ghrelin profile. Schaller et al. (2003) concluded that insulin was not a meal-related cause of the postprandial decline in ghrelin in monogastrics. Nevertheless, this does not explain why an infusion of triacylglycerols would reduce circulating ghrelin concentrations (Feinle-Bisset et al., 2005), or why Schaller et al. (2003) reported no effect of a slow glucose infusion on blood ghrelin while coinfusing insulin. These results imply that the stimulus for cessation of ghrelin production may be an energy signal, rather than a metabolite (e.g., glucose) per se. Further research is required to determine whether ruminally derived VFA have a negative effect on circulating plasma ghrelin, and whether this effect is dependent on the VFA in question.

The factors causing the postnadir rise in circulating ghrelin are unclear. Plasma ghrelin concentrations began to rise when glucose, insulin, and NEFA concentrations were $7 \mathrm{mmol} / \mathrm{L}, 20 \mathrm{mU} / \mathrm{L}$, and $0.34 \mathrm{mmol} / \mathrm{L}$, respectively, and at 12 to $13 \mathrm{~min}$ after the postnadir surge in epinephrine. Epinephrine does not cause an increase in plasma ghrelin (Mundinger et al., 2006), suggesting that one of the other blood constituents may be involved. The rise in ghrelin may be due to recognition of a declining energy supply (both NEFA and glucose concentrations are suppressed by insulin) and that meal initiation is necessary for survival. Such a hypothesis is consistent with the recognition of an energy signal by factors controlling ghrelin release and the ghrelin-induced hyperglycemia reported by Itoh et al. (2006) in lactating dairy cows. An alternative thesis could be that the stimulant for ghrelin release recognized elevated concentrations of insulin, and the rise in plasma ghrelin was a direct attempt to prevent fur- 

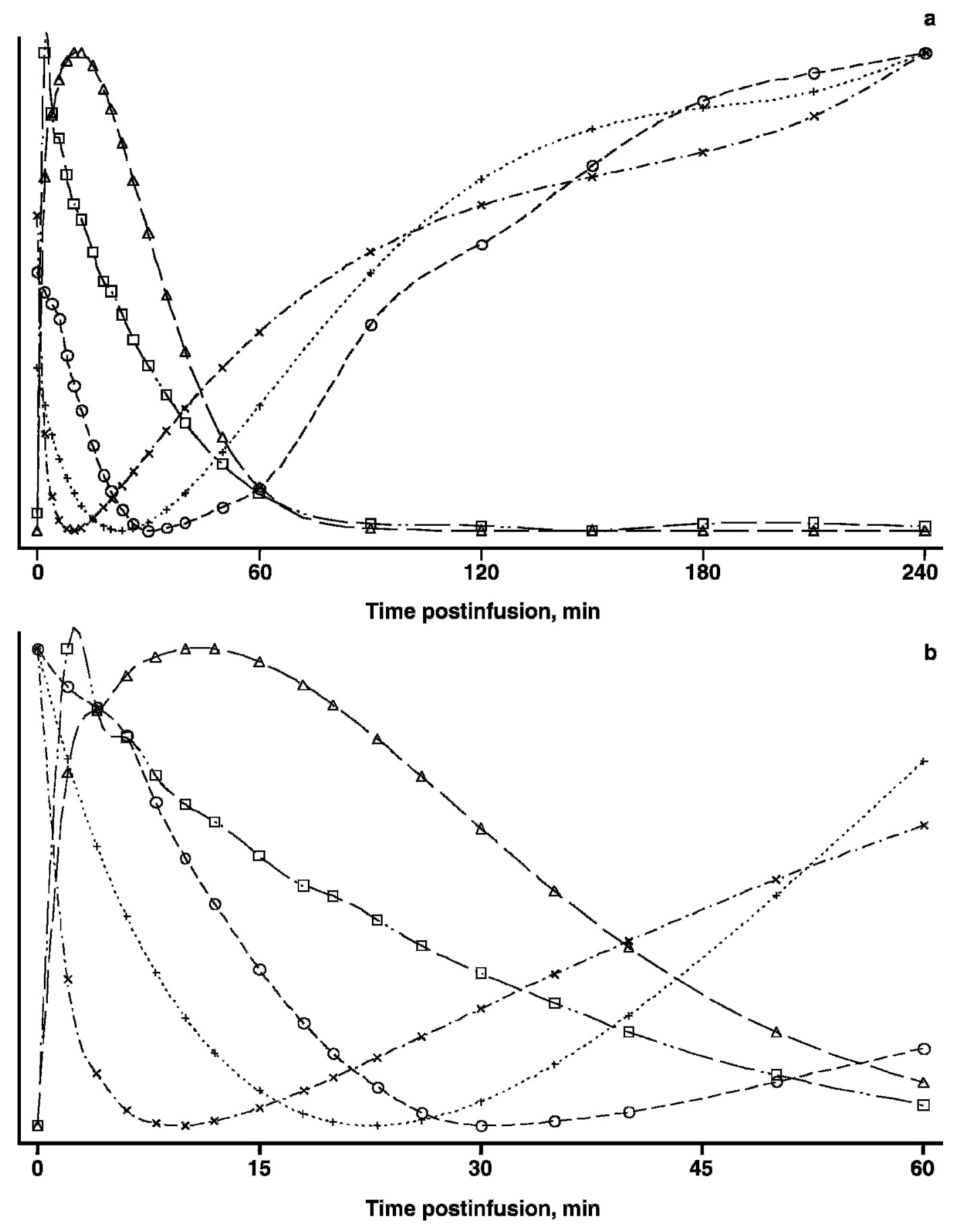

Figure 2. Collective portrayal of the profiles, scaled on a metabolite/hormone basis, illustrating the sequential nature of changes in plasma concentrations of glucose $(\square)$, insulin $(\triangle)$, NEFA $(\bigcirc)$, ghrelin $(+)$, and epinephrine $(\times)$ in early-lactating dairy cows $(n=10)$ following a jugular infusion of $300 \mathrm{mg}$ of D-glucose/kg of BW. Panels include (a) the entire observation period (240 min) and (b) the first 60 min postinfusion.

ther insulin secretion. Nonetheless, the considerable time period between peak insulin and the postnadir surge in ghrelin is not consistent with an insulin-mediated increase in ghrelin. Further research is required to determine the factor(s) influencing the preprandial rise in ghrelin production, if this knowledge is to be used to better understand the factors controlling and limiting DMI. 


\section{ACKNOWLEDGMENTS}

The authors acknowledge the technical assistance of J. Lee, P. Aspin, K. Watkins, and P. Gore, all the help afforded them by the Dexcel Lye dairy farm staff, and the laboratory expertise of Alpha Scientific (Hamilton, NZ). This work was funded by New Zealand Dairy Farmers through DairyNZ (Hamilton, NZ).

\section{REFERENCES}

Cass Terry, L., W. R. Crowley, and M. D. Johnson. 1982. Regulation of episodic growth hormone secretion by the central epinephrine system. J. Clin. Invest. 69:104-112.

Downing, J. A., J. Joss, P. Connell, and R. J. Scaramuzzi. 1995. Ovulation rate and the concentrations of gonadotrophic and metabolic hormones in ewes fed lupin grain. J. Reprod. Fertil. 103:137-145.

Feinle-Bisset, C., M. Patterson, M. A. Ghatei, S. R. Bloom, and M. Horowitz. 2005. Fat digestion is required for suppression of ghrelin and stimulation of peptide YY and pancreatic polypeptide by intraduodenal lipid. Am. J. Physiol. Endocrinol. Metab. 289:E948-E953.

Ferranini, E., S. Camastra, S. W. Coppack, D. Fliser, A. Golay, and A. Mitrakou. 1997. Insulin action and non-esterified fatty acids. Proc. Nutr. Soc. 56:753-761.

Gaynor, P. J., R. A. Erdman, B. B. Teter, A. V. Capuco, and D. R. Waldo. 1996. Glucose and norepinephrine challenges during abomasal infusion of cis or trans octadecenoates in Holstein cows. J. Dairy Sci. 79:1590-1595.

Goldstein, D. S., G. Z. Feuerstein, J. L. Izzo Jr., I. J. Kopin, and H. R. Keiser. 1981. Validity and reliability of liquid chromatography with electrochemical detection for measuring plasma levels of norepinephrine and epinephrine in man. Life Sci. 28:467-475.

Gutierrez, R. G., J. M. Linhart, and J. S. Pitblado. 2003. From the help desk: Local polynomial regression and Stata plugins. Stata J. 3:412-419.

Hales, C. N., and P. J. Randle. 1963. Immunoassay of insulin with insulin-antibody precipitate. Biochem. J. 88:137-146.

Hart, I. C., J. A. Bines, S. V. Morant, and J. L. Ridley. 1978. Endocrine control of energy metabolism in the cow: Comparison of the levels of hormones (prolactin, growth hormone, insulin and thyroxine) and metabolites in the plasma of high- and low-yielding cattle at various stages of lactation. J. Endocrinol. 77:333-345.
Itoh, F., T. Komatsu, S. Kushibiki, and K. Hodate. 2006. Effects of ghrelin injection on plasma concentrations of glucose, pancreatic hormones, and cortisol in Holstein dairy cattle. Comp. Biochem. Physiol. A 143:97-102.

Mundinger, T. O., D. E. Cummings, and G. J. Taborsky Jr. 2006. Direct stimulation of ghrelin secretion by sympathetic nerves. Endocrinology 147:2893-2901.

Nakai, Y., H. Hosoda, K. Nin, C. Ooya, H. Hayashi, T. Akamizu, and K. Kangawa. 2003. Plasma levels of active form of ghrelin during oral glucose tolerance test in patients with anorexia nervosa. Eur. J. Endocrinol. 149:R1-R3.

Nelson, D. L., and M. M. Cox. 2005. Lehninger Principles of Biochemistry. 4th rev. ed. W. H. Freeman and Company, New York, NY.

Reynolds, C. K. 2006. Production and metabolic effects of starch digestion in dairy cattle. Anim. Feed Sci. Technol. 130:78-94.

Roche, J. R., A. J. Sheahan, L. M. Chagas, and D. P. Berry. 2007. Concentrate supplementation reduces postprandial plasma ghrelin in dairy cows: A possible neuroendocrine basis for reduced pasture intake in supplemented cows. J. Dairy Sci. 90:1354-1363.

Schaller, G., A. Schmidt, J. Pleiner, W. Woloszczuk, M. Wolzt, and A. Luger. 2003. Plasma ghrelin concentrations are not regulated by glucose or insulin. Diabetes 52:16-20.

Shiiya, T., M. Nakazoto, M. Mizuta, Y. Date, M. S. Mondal, M. Tanaka, S.-I. Nozoe, H. Hosoda, K. Kangawa, and S. Matsukura. 2002. Plasma ghrelin levels in lean and obese humans and the effect of glucose on ghrelin secretion. J. Clin. Endocrinol. Metab. $87: 240-244$

StataCorp. 2005. Stata 9.0. StataCorp., College Station, TX.

Sugino, T., J. Yamaura, M. Yamagishi, A. Ogura, R. Hayashi, Y. Kurose, M. Kojima, K. Kangawa, Y. Hasegawa, and Y. Terashima. 2002. A transient surge of ghrelin secretion before feeding is modified by different feeding regimens in sheep. Biochem. Biophys. Res. Commun. 298:785-788.

Sumner, J. M., F. Valdez, and J. P. McNamara. 2007. Effects of chromium propionate on response to an intravenous glucose tolerance test in growing Holstein heifers. J. Dairy Sci. 90:3467-3474.

Tschop, M., D. L. Smiley, and M. L. Heiman. 2000. Ghrelin induces adiposity in rodents. Nature 407:908-913.

Wertz-Lutz, A. E., T. J. Knight, R. H. Pritchard, J. A. Daniel, J. A. Clapper, A. J. Smart, A. Trenkle, and D. C. Beitz. 2006. Circulating ghrelin concentrations fluctuate relative to nutritional status and influence feeding behavior in cattle. J. Anim. Sci. 84:3285-3300.

Wren, A. M., L. J. Seal, M. A. Cohen, A. E. Brynes, G. S. Frost, K. G. Murphy, W. S. Dhillo, M. A. Ghatei, and S. R. Bloom. 2001. Ghrelin enhances appetite and increases food intake in humans. J. Clin. Endocrinol. Metab. 86:5992-5995. 